\title{
AUTORITARISMO INSTRUMENTAL OU ÍNDOLE NACIONAL?
}

Tiago Losso

RESUMO: O conceito de autoritarismo instrumental, formulado por Wanderley Guilherme dos Santos, tem como finalidade designar as posturas autoritárias caracteristicas de alguns pensadores brasilciros das décadas de 1920, 30 e 40. Este tipo de autoritarismo, segundo Santos, teria como principal caracteristica a transitoriedade. Teria sido o meio encontrado por alguns autores para construir uma sociedade democrática através de métodos não democráticos. O trabalho aqui proposto irá questionar a argumentação que sustenta o conceito de Autoritarismo Instrumental. Para obter tal resultado, será efetivada uma análise da obra de Oliveira Vianna. Homem de letras e de Estado, Vianna não só pensou o Brasil mas também atuou politicamente, estando envolvido com a claboração da legislação trabalhista estadonovista. A comunicação será estruturada através do apontamento dos elementos textuais da obra de Vianna que podem apontar para a não transitoriedade do autoritarismo. Será proposta uma análise do significado de democracia, participação popular e condução dos negócios públicos, relacionando isto com os argumentos que sustentam o conceito de Autoritarismo Instrumental.

UNITERMOS: Autoritarismo, pensamento social, Oliveira Vianna.

$\mathrm{O}$ autoritarismo é uma marca do pensamento brasileiro do século XX. Em diversos matizes c claborado de formas mais ou menos substanciais, a marca autoritária está presente em grande número de análises feitas sobre a realidade brasileira. E destas análises surge um importante resultado: a sugestão de meios não democráticos para a resolução dos problemas brasileiros.

As décadas iniciais do século XX são um momento de aprofundamento das tensões envolvendo termos dicotômicos como autoritarismo/democracia, liberdade/controle, liberalismo/centralismo. Não só uma 
gama variada de elaborações intelectuais tem a autoridade - e autoritarismo - como tema central, como muitas diretrizes governamentais foram traçadas através destas posturas intelectuais.

O presente artigo irá analisar uma forma específica de autoritarismo. Mais especificamente, será aqui analisada a maneira como foi descrita a proposta autoritária de alguns pensadores brasileiros. Levando em conta que o início do século passado foi um momento de efervescência cultural e política, os homens de letras são chamados a intervir na condução dos negócios públicos, e homens públicos usam as letras para justificar suas decisões políticas. ${ }^{1}$ Imbricadas, ação política c reflexão social serão consideradas partes de uma mesma ação. Indissociáveis, scrão apontadas como forma única de empurrar o Brasil em dircção ao seu destino glorioso.

A década de 1930 é o paroxismo disto que afirmamos. Ao longo desta década, várias opções políticas e idcológicas estão em permanente confronto para tomar a dianteira no processo de transformação do Brasil. Em 10 de novembro de 1937 esta batalha chega ao fim, e a postura que então passa a orientar o Executivo Federal - ou uma destas posturas - scrá o foco das linhas que seguem.

O problema da organização nacional é algo presente no Brasil, pelo menos de forma mais declarada, desde o momento de autonomia da metrópole portuguesa. ${ }^{2}$ Não é despropositado, portanto, que esta preocupação esteja ligada ao momento de radicalização do processo político que a década de 1930 assiste, uma vez que

Entre 1930 e 1939 produzem-se no Brasil as mais argutas análise sobre o processo politico nacional, elaboram-se as princi-

\footnotetext{
1 Como afirma Bolivar Lamounier, uma das marcas de pensadores como Oliveira Vianna, Francisco Campos ou Azevedo Amaral é justamente se encaixarem cm “(...) uma tradição de pensamento que se formou tendo em vista a ação política, com evidente intenção de influir nos acontecimentos." cf. Lamounier in FAUSTO, 1977:345-346.

2 "Uma vez conquistada a autonomia perante a metrópole portuguesa, dois temas assumirão imediatamente a primazia sobre os demais: de que maneira organizar o novo Estado e de que maneira organizar politicamente a sociedade que se constituia." SANTOS, 1978:35.
} 
pais hipóteses sobre a formação e funcionamento do sistema social, c articula-se o conjunto de questões que, em verdade, permanecerão até hoje como o núcleo fundamental embora não exaustivo de problemas a serem resolvidos teórica e praticamente. Os debates se iniciam pela própria significação da revolução de 30 , envolvem os militares e sua relação com as demais forças sociais, retoma-se a questão da centralização , investigam-se as origens da crise nas sociedades modernas, estuda-se o impacto das sociedades avançadas em sociedades de desenvolvimento retardado, louva-se e critica-se o papel da elite e das massas no desenvolvimento social, esmiuçasse o passado nacional, pesando-se a contribuição de cada agrupamento econômico e social, elaboram-se os mais variados prognósticos sobre a provável evolução do sistema nacional. A emergência de movimentos autoritários, nacionalmente organizados, oferece novo material à especulação política sobre o papel dos partidos, das massas e das elites, enquanto o imediato passado, com as rebeldias tenentistas, e os surto comunista c integralista, em 1935 e 1938, descobrirão a temática da violência no processo político. ${ }^{3}$

Entre os diversos pontos de investigação social, sobressai a função do Estado na socicdade contemporânea e brasilcira. E os teóricos autoritários terão na relação do Estado com a sociedade um dos pontos fundamentais de sua análise.

O Movimento de 1930 traz para a esfera federal um grupo de autores/atores que convém aqui destacar. Oliveira Vianna, Azevedo Amaral e Francisco Campos estarão ligados, de diversas formas, ao primeiro governo de Vargas. Campos participa das conspirações que antecedem a subversão da ordem política cm 1930, atuando no aparato estatal ocupando pastas ministcriais, e culminando sua ação ao formular a Constituição de 1937 - já como Ministro da Justiça - que inaugura o Estado Novo. Vianna será técnico do Ministério do Trabalho, estando envolvido na elaboração de uma sé-

\footnotetext{
${ }^{3}$ SANTOS, 1978:38.
}

Temáticas, Campinas, 9(17/18):105-122, jan./dez. 2001 
ric de normas e leis trabalhistas que marcaram a era Vargas, sendo membro da Comissão Revisora das Leis da União (1939) e Ministro do Tribunal de Contas da União (1942). Amaral, por fim, pode scr apontado como um dos mais atuantes ideólogos do Estado Novo, já que de sua pena surgem interpretações que sustentam, aconselham e defendem a permanência do estado de exceção surgido $\mathrm{cm} 1937$.

Mesmo com pontos analíticos comuns, estes três autores não podem ser apontados como portadores e defensores de idéias idênticas. Antes de suas divergências, tome-se nota de suas concordâncias intelectuais.

Ao que interessa no momento, cabe uma observação sobre a forma como é encarado o aparato estatal sob a ótica destes três autores. A relação que estabelecem entre sociedade e Estado é de tal forma importante para a organização social, que Bolivar Lamounier os encaixa num conceito que denomina Ideologia de Estado. ${ }^{4}$ Este conjunto de idéias - das quais compartilham Campos, Vianna e Amaral - pressupõc, entre outras coisas, o aparecimento do Estado como órgão máximo da atividade política. Organizar, tutelar, canalizar interesses e coordenar o processo político são os pontos centrais desta visão de Estado. Assim, surge o csquema definitivo para colocar a sociedade nos seus devidos eixos. Um Estado que possui condições de gerir adequadamente a socicdade. ${ }^{5}$

O que mais aproxima Amaral, Vianna c Campos é justamente a defesa do Estado como ente político escolhido para organizar a sociedade. No entanto, as razões desta escolha afastam estes autores, alocando-os $\mathrm{cm}$ dois locais intelectuais distintos.

\footnotetext{
4 O autor estabelece oito critérios para esta classificação: 1) predominio do princípio "estatal" sobre o princípio de "mercado"; 2) visão orgânica-corporativa da sociedade; 3)Objetivismo tecnocrático; 4) visão autoritária do conflito social; 5) não organização da sociedade civil; 6) não mobilização politica; 7) clitismo e voluntarismo como visão dos processos de mudança política; 8) o leviatã benevolente. cf. LAMOUNIER, op. cit. p. 359.

${ }^{5}$ De forma mais detalhada, Lamounier aponta as dimensòes de cada um dos oito pontos acima mencionados. Uma análise deste conjunto de pressupostos foge ao nosso objetivo, mas pode ser conferido cm LAMOUNIER, op. cit. ps. 359-370.
} 
No caso de Azevedo Amaral a urgência de hipertrofia das prerrogativas estatais reside nas necessidades e características do mundo contemporâneo $\mathrm{e}$ da realidade brasilcira. No tocante à situação internacional, a própria essência do século XX colocava $\mathrm{cm}$ cheque a validade do liberalismo político:

Para ele [Amaral], o século XX, já àquela altura caracterizado pela extrema turbulência de guerras e de revoluções que se sucediam e se entrecruzavam, cra o século da revolução e da contra-revolução - do "revolucionismo" - em oposição ao século XIX, que havia sido aquele do "evolucionismo". 6

Um mundo cujo caos precisa ser controlado. E uma das primeiras atitudes era controlar o excesso de liberdade característico do liberalismo:

Azevedo Amaral via o Estado liberal c o laissez-faire como produtos de uma época específica, historicamente em vias de serem superados: ambos eram vistos como uma montagem políticoinstitucional que garantia os interesses das "classes dirigentes". 7

No Brasil, a situação deste "desequilíbrio" era ainda mais trágica, uma vez que se somavam, em solo nacional, a inadequação do liberalismo ao mundo contemporâneo e à realidade nacional, aos hábitos nacionais:

No dia em que se tiverem dissipado completamente do nosso espírito as últimas névoas formadas pela ilusão democráticoliberal, sentiremos acanhamento, senão positiva vergonha, ao lembrarmo-nos que assistimos, durante tantas dezenas de anos, ao grotesco funcionamento de um simulacro de sistema representativo, tão alheio às nossas realidades nacionais, que não sabíamos sequer executar fielmente a imitação das suas exterioridades. A prática do sufrágio universal e da eleição direta no Brasil fornece realmente assunto mais adequado a servir de matéria-prima ao humorista, que ao estudo sério de historiadores. ${ }^{8}$

6 MEDEIROS: $1978: 54$.

${ }^{7}$ MEDEIROS, 1978:55.

8 AMARAL apud MEDEIROS, 1978:58-59.

Temáticas, Campinas, 9(17/18):105-122, jan./dez. 2001 
O liberalismo era, portanto, uma farsa sob dois aspectos: $\mathrm{cm}$ relação à situação do mundo contemporâneo $\mathrm{c} \mathrm{cm}$ relação à realidade brasileira. Francisco Campos possui o mesmo tipo de ressalvas em relação aos jogos políticos liberais-democráticos.

Político minciro de expressão ao longo das décadas de 1910 e 1920 , Campos acaba passando para a história como o mentor de uma supressão das liberdades políticas e dos jogos políticos democráticos ao claborar a constituição que inaugura a ditadura de Vargas. A hipertrofia das prerrogativas estatais, nesse caso centradas na figura do ditador, será a marca desta constituição e o norte do regime de 1937, como demonstra o seguinte trecho:

As abstrações, as coletividades, os parlamentos, os conselhos, as entidades incorpóreas ou idćias não são capazes de vontade, de decisão e de responsabilidade. Se a politica é, por excelência, o dominio da vontade, da decisão e da responsabilidade, a primeira categoria da política, a categoria fundamental, há de ser a pessoa - a pessoa que decide, o centro de vontade e de responsabilidade, o chefe, o homem que a confiança pública aceita ou designa como encarnação do Estado.?

Ou ainda, referindo-se ao Estado Novo:

Nós podemos dizer, a esta altura do regime, que o Estado Novo é o Presidente - a realização de scus intuitos, o desdobramento do seu programa, a projeção da sua vontade - e nela tem o seu mais provecto doutrinador e defensor mais intransigente e valioso. ${ }^{10}$

Tanto Campos como Amaral acreditaram ter encontrado no Estado Novo aquilo que almejavam para a sociedade: democracia não-democrática. Aos olhos destes dois autores, o autoritarismo daria ao Brasil, finalmente, um regime de acordo com as urgências da contemporaneidade, criando as-

\footnotetext{
' CAMPOS, 1983:252.

10 CAMPOS, 1983:180.
} 
sim, uma sociedade justa, coisa que seria impensável sob um regime democrático nos moldes liberais. A seguinte passagem exemplifica a forma pela qual democracia c autoritarismo são fundidos, aos olhos de Campos, $\mathrm{cm}$ um mesmo regime - o Estado Novo:

É desnecessário insistir em que o Estado Brasileiro, sendo democrático, é também autoritário, cabendo ao Presidente da República a autoridade suprema, exercida $\mathrm{cm}$ nome do povo e no interesse do seu bem estar, da sua honra, da sua independência e da sua prosperidade. ${ }^{11}$

O autoritarismo, portanto, é a forma apontada e scguida por Campos c Amaral para organizar o Brasil. Esta também é a opinião de Oliveira Vianna, mas por outros motivos que não a situação do mundo contemporâneo.

Oliveira Vianna estrutura sua reflexão sobre o Brasil partindo de uma análise da formação do país. Populações Meridionais do Brasil é a tentativa de mapear a estruturação política brasileira. Estudando as primciras colonizações, as normas que regeram esta ocupação territorial, c a forma pela qual o poder político e a administração governamental estruturaram a realidade brasileira, Vianna desemboca sua argumentação no diagnóstico de que as estruturas políticas brasileiras são inadaptáveis ao liberalismo político. Conseqüentemente, continua o autor fluminense, a democracia, no Brasil, é uma forma equivocada de organização política e social. Para comprovar, basta observar o caos que se instala no Brasil após a Proclamação da República e adoção de normas liberais de organização nacional, consubstanciadas na Constituição de 1891. Assim, aos olhos de Vianna, a democracia é impraticável no Brasil, acima de tudo, em virtude da formação específica da realidade nacional, estruturada em torno do poder político local, do centrifuguismo político e administrativo e dos desmandos patrocinados pelos chefes políticos locais. Para sanar esta fragilidade, Vianna sugere a necessidade

"CAMPOS, 1983:154.

Temáticas, Campinas, 9(17/18):105-122, jan./dez. 2001 
de um regime de acordo com o "caráter nacional": centralizado, centralizador c autoritário. Como afirma Santos:

Em 1920, Oliveira Vianna expressou pela primeira vez, tão clara e completamente quanto possivel, o dilema do liberalismo no Brasil. Não existe um sistema um sistema politico liberal, dirá ele, sem uma sociedade liberal. O Brasil, continua, não possui uma sociedade liberal mas, ao contrário, parental, clânica e autoritária. Em conseqüência, um sistema político liberal não apresentará desempenho apropriado, produzindo resultados sempre opostos aos pretendidos pela doutrina. Além do mais, não há um caminho nattral pelo qual a sociedade brasileira possa progredir do estágio em que se encontra até tornar-se liberal. Assim, concluiria Oliveira Vianna, o Brasil precisa de um sistema político autoritário cujo programa econômico e politico seja capaz de demolir as condições que impedem o sistema social de se transformar $\mathrm{cm}$ liberal. Em outras palavras, seria necessário um sistema político autoritário para que se pudesse construir uma sociedade liberal. ${ }^{12}$

Nota-se, portanto, que para Vianna, o autoritarismo seria, na interpretação de Santos, a estrada que conduziria o Brasil até uma sociedade liberal. Santos cunha, então, o termo Autoritarismo Instrumental. Este conceito pretende dar conta da postura que este autor identifica na produção intelectual de alguns pensadores autoritários brasileiros: a transitoricdade de um sistema político autoritário, mantido até o momento $\mathrm{cm}$ que a sociedade estivesse pronta para ingressar $\mathrm{cm}$ um sistema político liberal.

Entre os defensores do autoritarismo no Brasil dos anos de 1930, as interpretações possuem algumas particularidades. Pode ser apontado o autoritarismo mobilizador c romântico dos integralistas, que preconizavam uma sociedade coordenada c controlada por um grupo de pessoas imbuídas dos mais altos valores $\mathrm{e}$ interesses nacionais. $\mathrm{O}$ autoritarismo centrado na figura do Estado, no qual a necessidade de métodos autoritários seria basicamente uma necessidade "natural" da sociedade - como no caso de Cam-

${ }^{12}$ SANTOS, 1978:93. Grifado no original.

Temáticas, Campinas, 9(17/18):105-122, jan./dez. 2001 
pos e Amaral.13 No caso dos autoritários "naturalistas", o autoritarismo se apresenta da seguinte forma:

Os sistemas autoritários não seriam, portanto, de acordo com esta linha de pensamento autoritário, naturalmente legitimos, mas apenas na medida $\mathrm{em}$ que evitem que conflitos generalizados destruam completamente a estrutura social c sejam capazes de distribuir, a cada parte envolvida nos conflitos, seu justo ganho. ${ }^{14}$

Um mal necessário, portanto. E não transitório, mas sim com a tendência de recrudescimento:

Não obstante, apesar de todas as diferenças os dois grupos [integralistas e autoritários "naturalistas] acreditam que o autoritarismo não é uma situação transitória devido a causas conjunturais. Ao contrário, quanto mais a sociedade progride, mas necessários se farão os regimes autoritários. E nisto, precisamente, reside a diferença entre eles e o grupo que denominei de autoritários instrumentais. ${ }^{15}$

A idéia de autoritarismo instrumental reside em duas caracterizações básicas. Em primeiro lugar, segundo Santos, os instrumentais não concebem a sociedade como possuidora de um sentido único e natural de desenvolvimento, o que abre espaço para a intromissão do Estado na condução deste desenvolvimento. Em segundo lugar, ainda segundo Santos, estes autoritários defendem a idéia de que o autoritarismo é a forma mais rápida e pertinente de encaminhar o país em direção à uma ordem liberal, quando desaparece a necessidade do autoritarismo. ${ }^{16} \mathrm{E}$ será $\mathrm{cm}$ Oliveira Vianna que Wanderley Guilherme dos Santos encontrará o maior representante do autoritarismo instrumental. Santos elabora - com um refinamento maior do

${ }^{13}$ Sobre o integralismo, cf. Araújo: 1987. Sobre a "naturalidade" do autoritarismo de Campos e Amaral, cf. SANTOS, 1978: 101 e seguintes.

${ }^{1+}$ SANTOS, 1978:102.

15 SANTOS, 1978:102-103.

16 SANTOS, 1978:103.

Temáticas, Campinas, 9(17/18):105-122, jan./dez. 2001 
que foi aqui feito - um panorama das preocupações intelectuais e conclusões argumentativas de Vianna. Vianna parte da análise da colonização brasileira - como apontado antes - para compreender a política nacional de sua época. Uma formação histórica marcada pela escassez de regulação por parte do poder público constituído, os chefes locais como senhores absolutos de vastas regiões territoriais, a população subjugada por estes chefes políticos locais (e deles dependentes) - são características que marcavam, aos olhos de Vianna, de forma cruel, a realidade brasileira do século XX. Uma tentativa de organização liberal, numa sociedade marcada desta forma pelo personalismo c pelo autoritarismo, uma vacina: o autoritarismo. Como Santos afirma: transitório, até que a sociedade estivesse pronta para o liberalismo. ${ }^{17}$

As linhas que seguem serão estruturadas no sentido de claborar uma contraposição à "transitoriedade" do autoritarismo contido nos escritos de Oliveira Vianna. Com tal objetivo, iremos nos deter $\mathrm{cm}$ alguns pontos de sua argumentação, propondo algumas interpretações diferentes das claboradas por Wanderley Guilherme dos Santos.

Como já foi dito antes, a formação do Brasil é um elemento essencial na argumentação elaborada por Vianna para defender a inviabilidade da democracia no Brasil. Santos interpreta esta questão atribuindo a Vianna uma intenção de educar a elite, no sentido de prepará-la para atuar numa sociedade liberal. Mas e se este apego das elites brasileiras ao personalismo e ao mandonismo for algo já constitutivo da sociedade, um elemento indissociável desta elite? Como então supor um momento de superação deste

\footnotetext{
17 SANTOS, 1978:104-107. Convém alguns esclarecimentos. O próprio Santos, em alguns momentos, faz o papel de advogado do diabo, e aponta possíveis falhas na transitoriedade do autoritarismo que vislumbra em Oliveira Vianna. Uma destas possiveis falhas seria, por exemplo, a inexistência, em Vianna, de uma agenda de transformações com o sentido de liberalizar a sociedade: "E apesar de ter colaborado na elaboraçĩo do código trabalhista e na montagem da estrutura judicial, destinada a administrar os conflitos industriais, parece-me que nunca compreendeu totalmente onde deveria procurar os atores politicos capazes de transformar a socicdade brasileira $\mathrm{em}$ uma comunidade liberal. Seu pensamento estava sempre voltado para uma elite politica especial, vinda não se sabe de onde, c que transformaria a cultura política brasileira de tal forma que a sociedade se tornaria liberal mediante maciça conversão natural." SANTOS, 1978:106.
} 
modo de relação elites-povo? Vianna acredita que a democracia funciona. Mas não no Brasil. Parcelas da Europa são um exemplo de como a democracia pode funcionar, desde que siga alguma regras. Ao comentar a formação politica européia, Vianna esclarece um dos motivos pelos quais a democracia funciona na Europa:

Estas "comunidades de aldeia" são, assim, puras democracias; existiam há milênios e existem ainda por toda a Europa. Toda a humanidade curopéia evoluiu, desde seus primórdios, sob este regime de vivência política. ${ }^{18}$

Daí decorre a familiaridade deste povo em participar de forma direta da política, cm comunidade:

Daí vem que o regime democrático, inclusive o hábito de acorrer aos comícios, representa, nesses povos europeus, uma tradição imemorial. ${ }^{19}$

E no Brasil, como se deu a "iniciação" política da massa? Como acredita Vianna, isto mostra a inviabilidade da democracia entre nós:

O povo-massa nunca teve participação, nem direta, nem de direito, no governo destas comunas, no periodo colonial. Quando influiam, era por intermédio dos procuradores do povo. Estes, porém, não pertenciam, pelo status, ao povo massa, embora lhe fossem os representantes ou delegados: era também gente da elite, da nobreza, homens de qualificação. ${ }^{20}$

Mais do que não participar das decisões, o povo assiste a uma sociedade que não é democrática. Pelo menos não nos padrões liberais, que possuem seu espelho na realidade histórica européia. A realidade do Brasil Co-

\footnotetext{
${ }^{18}$ VIANNA, 1974(a):95.

19 VIANNA, 1974(a):96.

${ }^{20}$ VIANNA, 1974(a):135. Grifado no Original.
}

Temáticas, Campinas, 9(17/18):105-122, jan./dez. 2001 
lônia foi marcada pela autonomia das administrações municipais - o centrifuguismo do poder local - mas nunca pela democracia.. ${ }^{21}$

A realidade do Brasil, portanto, não é a realidade democrática curopéia. Por que, então, pergunta Oliveira Vianna, pretende-se estabelecer no Brasil um regime de acordo com a realidade de outros países? Um autoritarismo instrumental, transitório, teria que ser capaz de lidar e reformular os padrões que regem a conduta política no Brasil. Das elites e da massa. Fundar mais uma vez a nação, desta vez cm moldes democráticos. E isso seria feito através de uma Estado autoritário? Talvez, scguindo as afirmações de Santos. Mas como mostra o próprio autor, Vianna nunca deixou claro como seria a educação da elites para a formatação de um novo padrão de comportamento político. Pelo contrário, o Estado Novo, experiência autoritária que poderia ser o motor desta transformação, fez aprofundar a relação política que Vianna credita à "natureza" brasilcira: uma elite que controla uma massa de incapazes para a participação nos negócios públicos. A centralidade do Estado na condução da política nacional é apontada na seguinte passagem de um comentador da obra de Vianna:

O Estatismo ć o ponto de partida mais abrangente da ideologia politica subjacente ao pensamento de OLIVEIRA VIANNA. O fortalecimento da autoridade estatal, realizado através da centralização política e da hipertrofia do Poder Exccutivo central, funciona, na verdade, como um princípio normativo que regula o conjunto de suas propostas. O Estado surge como o demiurgo e agente civilizador de uma sociedade marcada pelo cgoísmo, pelo individualismo, pelo facciosismo $\mathrm{e}$ pela ausência de direção dos grupos que a compõem. ${ }^{22}$

Um segundo ponto da argumentação de Vianna é o caráter pernicioso, do ponto de vista cultural, decorrente da inexistência de um poder central efetivo na formação nacional. Como pretender formar uma nação de

\footnotetext{
21 VIANNA, 1974(a):147.

22 SILVA, 1999:04. Grifado no original.
}

Temáticas, Campinas, 9(17/18):105-122, jan./dez. 2001 
um aglomerado populacional que não compartilha o sentimento de pertencimento a um todo político?:

(...) vê-se claramente que os pressupostos funcionais de uma estrutura democrática moderna, de tipo Estado-Nação, há de Ter o seu assento principal num "complexo cultural" que deve ser anterior c preliminar à instituição desse tipo de Estado (.... $)^{23}$

E qual a implicação dos componentes culturais para efetivar transformações de cunho político ou social? A advertência de Vianna neste sentido é fundamental para compreender sua argumentação:

(...) no planejamento de qualquer reforma politica ou de qualquer reforma social, que importe uma mudança de conduta ou alteração do comportamento babitual do povo - o primeiro ponto a esclarecer, a conhecer ou a atender há de ser o exame das condições culturais do povo, a análise de suas tradições vivas, dos seus usos e costumes : - disto dependerá o Gexito ou o fracasso da reforma em causa. ${ }^{24}$

Após aproximadamente 300 anos de cultura autoritária, centrada na figura do chefe político local, dependendo deste para manter-se e criar prole, quanto tempo de autoritarismo transitório, instrumental e educativo o "povo-massa" vai necessitar para poder participar da vida política nacional?

Oliveira Vianna aponta a existência de duas técnicas que possibilitam a mudança social: a autoritária $\mathrm{e}$ a liberal. Em ambas as técnicas, muito pouco o Estado pode fazer contra a índole do povo. No caso da técnica liberal:

Dentro de um regime liberal - de permissão, de concessão, de faculdade - é certo que nosso direito-costume, que é o direito do povo massa, vencerá o direito-lei, que porventura venha estabelecer em nosso povo, uma minoria de "golpistas" irrefletidos. ${ }^{25}$

\footnotetext{
23 VIANNA, 1974(a):165. Grifado no original.

24 VIANNA, 1974(b): 111.

25 VIANNA, 1974(b):117. Grifado no original.
}

Temáticas, Campinas, 9(17/18):105-122, jan./dez. 2001 
No caso do Brasil, portanto, com uma tradição política não democrática, não scrá a liberdade o meio mais efetivo de claborar e efetivar mudanças sociais. Abre-sc, então, o caminho para o estabclecimento de uma agenda controlada pelo Estado. Mas o próprio Vianna aponta as dificuldades de contrapor medidas de transformação social à indole do povo:

(...) unicamente a coação pura e material do Estado não basta para levar um povo à prática de qualquer regime contrário à sua indole c aos seus costumes. Esta coação pura e simples pode resultar até contraproducente: é o caso do fascismo e é o caso do nazismo. Scria o caso do Brasil com o Comunismo, que importaria aqui uma torção violenta imposta à nossa estrutura tradicional. ${ }^{26}$

Poderíamos dizer: não só o comunismo como também o liberalismo seriam uma violação dos costumes e da índole brasileira. Pode ser aventada a seguinte resposta: mas através da educação, o povo brasileiro pode se acostumar e agir politicamente dentro de padrões liberais. Sim, mas se o "povo-massa" é suficientemente plástico para se moldar a uma estrutura política liberal e democrática - indo contra séculos de imersão numa política autoritária c personalista -, porque não se pode transformá-lo cm um participante do jogo político nos moldes "comunistas"?

A resposta que acreditamos ser a mais cocrente é que Oliveira Vianna não acredita na plasticidade do indivíduo c da sociedade. Wanderley Guilherme dos Santos o distingue de outros autoritários (como já mostramos) que naturalizam a necessidade do autoritarismo na estruturação social. Mas Vianna, cm nossa interpretação, mesmo não naturalizando o autoritarismo, vai "historicizá-lo".

Analisando as estruturas sociais brasileiras, desde as primeiras ocupações territoriais, Vianna conclui que a única forma possivel de organização social e política no Brasil é o autoritarismo. Como uma maldição, o Brasil

26 VIANNA, 1974(b):129.

Temáticas, Campinas, 9(17/18):105-122, jan./dez. 2001 
não pode fugir àquilo que foi construído ao longo de séculos. Como uma marca, a autoridade está definitivamente agregada ao caráter do povo, das elites e do país. Costumes, instituições, práticas, visão de mundo: o autoritarismo perpassa todas as dimensões da vida brasileira. ${ }^{27}$

Nesse sentido, a possibilidade da transitoriedade do autoritarismo, colocando o Brasil no caminho de uma sociedade liberal e democrática fica frágil e incerta. O latifúndio, na perspectiva de Oliveira Vianna formata a sociedade brasileira, assim como a pequena aldeia curopéia cria a possibilidade da democracia:

Desde a nossa vida econômica à nossa vida moral, sentimos, sempre, poderosa, e influência conformadora do latifúndio; este é, na realidade, o grande medalhador da sociedade e do temperamento nacional. ${ }^{2 s}$

E agregado ao latifúndio, um dos pontos centrais do pensamento de Vianna, mescla-se na conformação do tipo nacional: a mestiçagem. Classe social e ctnia formam um todo inseparável. E as classes inferiores são as "raças inferiores". Na formação nacional, a "plebe" será composta de tipos "raciais inferiores"; c a clite, de tipos "raciais superiores". ${ }^{29}$

Assim, além da conformação histórica que impede o surgimento de uma socicdade democrática, tem-se também uma situação étnica em que uma sociedade hicrarquizada "racialmente" não pode ser equalizada $\mathrm{cm}$ termos políticos.

\footnotetext{
27 Não será gratuita a idẻia de criar "técnicas" de governo $\mathrm{cm}$ consonância com as necessidades brasileiras. Os Conselhos Técnicos seriam um exemplo desta idéia: "No conjunto da arquitetura institucional do Estado autoritário, tal como idealizado por OLIVEIRA VIANNA, desponta a instituição dos Conselhos Técnicos como locıs estratégico do qual a política estatal poderia ser concebida de maneira 'objetiva', segundo os imperativos da ciência e da técnica. Além disso, os Conselhos eram pensados como instituiçōes relativamente impermeáveis aos males de nossa cultura politica, mantendo-se distante da influência de políticos c de partidos movidos pelo 'espirito de clã' e pelo facciosismo". SILVA, 1999:09. Grifado no original.

28 VIANNA, 1987:54. Grifado no original.

29 VIANNA, 1987:106-107.
} 
Fadados a lidar com um passado incontornável, resta ao Brasil alicerçar seu momento político nas necessidades historicamente construídas. $\mathrm{O}$ edifício político brasileiro terá como um de scus elementos constitutivos a autoridade - o autoritarismo. Sobre outras bases, a cstrutura social desaba, como vinha acontecendo desde 1891, quando um código liberal pretendeu estruturar uma sociedade não democrática $\mathrm{cm}$ sua essência. Os anos de 1930 marcam o momento do encontro do país real com o país legal, numa terminologia cara a Vianna. Num país sem vida democrática, o liberalismo não é realizável. Ao Brasil resta accitar e lidar da melhor maneira possivel com sua "indole":

É que nós não temos propriamente uma evolução política, no verdadeiro sentido da expressão. Não se verifica aqui aquela seriação, que os evolucionistas estabelecem para a transformação histórica das formas de governo: da monarquia para a aristocracia e desta para a democracia, numa complicação crescente de órgãos e funções. Entre nós, os órgãos e as funções do poder público mostram-se completos e diferenciados desde a sua nascença. ${ }^{30}$

\begin{abstract}
The concept of ins/rmmental autboritariamism, which was proposed by Wanderley Guilherme dos Santos, objetctives to describe the authoritarian positions adopted by some brazilian philosophers trough the $1920^{\circ} \mathrm{s}, 30^{\prime} \mathrm{s}$ and $40^{\prime} \mathrm{s}$. According to the author, the main characteristic of this kind of authoritarianism is to be transitory. It could be the way some authors chose to create a democratic socicty through non-democratic methods. This work will question the argumentation that sustains this concept. For this purpose, it is analyzed the works of Oliveira Vianna. Man of letters and state, this author not just analyzed Brazil, but was a politician involved in the elaboration of the working legislation of the Estado Novo. It is pointed out some textual elements used by Vianna, wich could demonstrate the nontransitory characteristic of the authoritaianism. It is proposed and analysis of the meaning of democracy, popular participation, and public business running, relating them to the arguments that sustain the concept os instrumental autborilarianism.
\end{abstract}

KEYwORDS: Authoritarianism, social thinking, Oliveira Vianna

${ }^{30}$ VIANNA, 1987:245.

Temáticas, Campinas, 9(17/18):105-122, jan./dez. 2001 


\section{REFERÊNCIAS BIBLIOGRÁFICAS}

ARAÚJO, Ricardo Benzaquem de. Totalitarismo e Revolução: o integralismo de Plinio Salgado. Rio de Janeiro: Jorge Zahar Editor, 1987.

BASTOS, Élide Rugai. MORAES, João Quartim de.(orgs) O pensamento de Oliveira Vianna. Campinas: UNICAMP, 1993.

BRESCIANI, Maria Stella Martins. A Concepção de Estado em Oliveira Vianna. In: Revista de História. São Paulo, n. 94, 1973.

CAMPOS, Francisco. O Estado Nacional e outros ensaios. Brasília: Câmara dos Deputados, 1983.

LAMOUNIER, Bolívar. "Formação de Um Pensamento Político Autoritário na Primeira República: uma Interpretação". in: FAUSTO, Boris. (org.) O Brasil Republicano, tomo III, vol. 1 (História da geral da civilização brasileira, 9). São Paulo: Difel, 1977.

MARTINS, Luciano. A Gênese de uma intelligentsia - os intelectuais e a politica no Brasil, 1920-1940. Revista Brasileira de Ciências Sociais, n. 4, jun, vol 2, Junho de 1987, pp. 65-87.

MEDEIROS, Jarbas. Ideologia Autoritária no Brasil, 1930-1945. Rio de Janeiro: Ed. Fundação Getúlio Vargas, 1978.

MORAES, João Quartim de. Joaquim Costa, Oliveira Vianna e a Revolução Pelo Alto. Campinas: Universidade Estadual, 1990.

OLIVEIRA, Lúcia Lippi de . Elite Intelectual c Debate Político nos anos 30. in: DADOS, Rio de Janciro, n. 22, 1979.

SANTOS, Wanderley Guilherme dos. Ordem Burguesa e Liberalismo Politico. São Paulo: Duas Cidades, 1978.

SILVA, Ricardo. Estado Autoritário e Tecnocracia: os Conselhos Técnicos no Pensamento de Oliveira Vianna. Florianópolis, 1999. Mimeo.

VIANNA, Francisco José de Oliveira. Ensaios Inéditos. Campinas: UNICAMP, 1991.

. Evolução do Povo Brasileiro; Evolução da Sociedade, Evolução da Raça, Evolução das Instituições Politicas. São Paulo: Montciro Lobato, s.d..

Paulo: José Olympio, 1949. O Idealismo da Constituição. São Paulo: Nacional, 1939. 
. Instituigõos Politicas Brasileiras (vol. 1). Rio de Janeiro: Record, 1974. (a). Instituiģoes Politicas Brasileiras (vol. 2). Rio de Janciro: Record, 1974. (b). - Pequenos Estudos de Psychologia Social. São Paulo: Nacional, 1942. . Populações Meridionais do Brasil: bistória, organização, psicologia. v.1. Populações rurais do centro-sul. 7 ed. - v.2. O campeador rio-grandense. 3 ed.. Belo Horizonte: Itatiaia, 1987. Niterói: Editora da Universidade Federal Fluminense, 1987.

. Problemas de Organização e Problemas de Diregão: o Povo e o Governo. Rio de Janeiro: José Olympio, 1952. . Problemas de Politica Objetiva. São Paulo: Nacional, 1947.

VIEIRA, Evaldo. Autoritarismo e Corporativismo no Brasil. (Oliveira Vianna e Companbia). São Paulo: Cortez, 1981. 